\title{
Circularly Polarized Printed Helix Antenna for L- and S-Bands Applications
}

\author{
Amir SIAHCHESHM ${ }^{1}$, Javad NOURINIA ${ }^{2}$, Changiz GHOBADI ${ }^{2}$, Majid SHOKRI $^{2}$ \\ ${ }^{1}$ Department of Electrical Engineering, Salmas Branch, Islamic Azad University, Salmas, Iran \\ ${ }^{2}$ Department of Electrical Engineering, Urmia University, Urmia, Iran
}

a_siahcheshm@iausalmas.ac.ir,j.nourinia@urmia.ac.ir, ch.ghobadi@urmia.ac.ir,m.shokri@urmia.ac.ir

Submitted July 16, 2019 / Accepted January 27, 2020

\begin{abstract}
The first aim of this work is to design a new geometry of printed helix antennas in a simple structure that only uses planar FR4 substrates, unlike conventional wire helix antennas. The main body of helix comprises four rectangular substrates containing helix arms forming a box. The printed helix arms are designed in a way that they meet each other in the edges of substrates when placed next to one another. The most important advantages of this work are introducing a method that makes the helix antenna fabrication and also the impedance matching procedure simpler. The presented helix antenna has endfire radiation in Z-direction with circular polarization suitable for L-and S-bands applications. Simulated and measured results show that the proposed antenna has a wide impedance bandwidth of $1.37 \mathrm{GHz}$ from $1.56 \mathrm{GHz}$ to $2.93 \mathrm{GHz}$ (more than 61\%), the $3 \mathrm{~dB}$ axial ratio bandwidth of $1.18 \mathrm{GHz}$ from $1.58 \mathrm{GHz}$ to $2.76 \mathrm{GHz}$ (more than $54 \%$ ) and a maximum gain of $11.3 \mathrm{dBiC}$ at $1.6 \mathrm{GHz}$.
\end{abstract}

\section{Keywords}

Helix antenna, end-fire radiation pattern, circular polarization, L- and S-bands applications

\section{Introduction}

Circularly Polarized (CP) antennas have excellent behavior in adverse weather conditions and motive transceivers, hence they are used widely in wireless communication systems [1-4]. One of the popular antennas with CP operation is the axial-mode helix antenna. Conventional wire helical antennas, known as a type of traveling wave antennas, have excellent CP characteristics [5]. Unfortunately, these helical antennas are not appropriate for compact terminals, and their fabrication and impedance matching process are tedious. To solve this problem, several designs with different techniques have been reported in the past years. In [6], a planar helical antenna is described, which is utilizing printed strips with straight-edge connections implemented by plated via-holes. In [7], an origami reconfig- urable axial-mode bifilar helical antenna is offered. In this design, an analytical method is developed for designing an origami helical antenna that mimics a standard helical antenna. By employing a parasitic circular patch over a strip-helix, two nearby CP resonances are created and the Axial Ratio (AR) bandwidth is improved [8]. Likewise, conical and inverted conical printed quadrifilar helical antennas in [9], a helical antenna with non-uniform pitch profile in [10], and quadrafilar helix antenna used on Alsat-1 S-band transmitter in [11] are the other works reported about helix antennas.

On the other hand, the impedance matching at the feed point is an important challenge for helix antennas. It is well-known that for a peripherally-fed in a helix antenna, a $50 \Omega$ impedance matching with a coaxial cable in the feed point is not realized. Subsequently, several impedance matching methods for helix antennas have been proposed to suppress this mismatch [12]. The methods involve tapering helical turns [13], [14], flattening a helical wire near the feed point [14], [16], [17], and utilizing a tapered transmission line as a midsection between a 50 -ohm feeding coaxial cable and the antenna input [18], [19], [20]. An innovative method, for solving impedance matching problem is introduced in this work which is simpler than the above-mentioned methods.

In this work, by using four planar substrates, an axialmode helix antenna is realized with a wide impedance and axial ratio bandwidths. Using planar substrates makes the antenna fabrication much simpler than conventional wire helix antennas. Also, the impedance matching problem of conventional helix antennas is solved by soldering the interior conductor of SMA to the lowest helix arm located above the ground plane. The dimensions of the proposed helix antenna are $35 \times 35 \times 155 \mathrm{~mm}^{3}$ for the main body and $150 \mathrm{~mm}$ for the square ground plane width. The antenna has a wide impedance bandwidth (IBW) of $1.37 \mathrm{GHz}$ from $1.56 \mathrm{GHz}$ to $2.93 \mathrm{GHz}$ and the $3 \mathrm{~dB}$ axial ratio bandwidth (ARBW) of $1.18 \mathrm{GHz}$ from $1.58 \mathrm{GHz}$ to $2.76 \mathrm{GHz}$, which is suitable for satellite communication at L- and Sbands frequencies. In addition, this antenna with the directional pattern at the helix axis (Z-axis in this case) has an $11.3 \mathrm{dBiC}$ realized peak gain at $1.6 \mathrm{GHz}$ frequency. 


\section{Helix Antenna Design}

The suggested end-fire helix antenna is composed of four rectangular substrates containing helix arms, which are placed on a base substrate. Figure 1 demonstrates the geometry of the printed helix antenna in this work.

A 3D view of the helix antenna is shown in Fig. 1(a). In addition, for giving more details about how the four rectangular substrates are formed as a box, an expanded view of the presented antenna structure is exhibited in Fig. 1(b). The left-handed helix conductor arms are twisted along Z-axis on the four FR4 substrates and vertically placed in the middle of the ground plane.

Correspondingly, the base substrate not only contains the ground plane but also mechanically supports the helix body. The thickness of all the substrates used in this design is chosen to be $0.8 \mathrm{~mm}$ with a relative permittivity of 4.4 . The helix antenna is fed with a coaxial cable by an SMA connector in the helix starting arm at one of the box edges. The interior conductor of SMA is soldered to the lowest helix arm which is located above the ground plane, and the

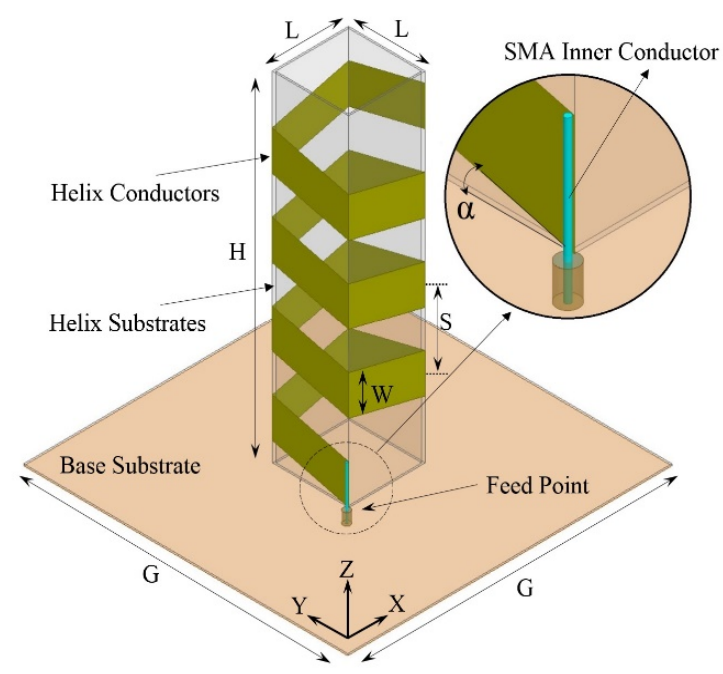

(a)

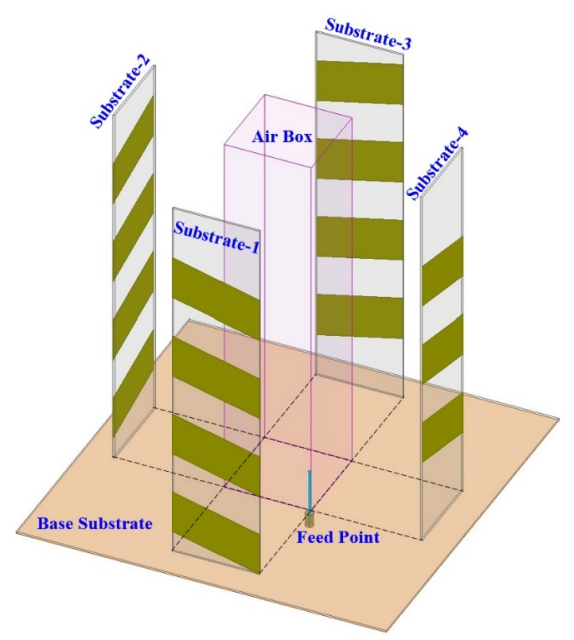

(b)

Fig. 1. The helix antenna configuration: (a) 3D view, and (b) expanded view.

\begin{tabular}{|c|c|c|c|c|c|c|}
\hline & $\begin{array}{c}\boldsymbol{C}=\mathbf{4} \times \boldsymbol{L} \\
(\mathbf{m m})\end{array}$ & $\begin{array}{c}\boldsymbol{W} \\
(\mathbf{m m})\end{array}$ & $\begin{array}{c}\boldsymbol{S} \\
(\mathbf{m m})\end{array}$ & $\begin{array}{c}\boldsymbol{G} \\
(\mathbf{m m})\end{array}$ & $\begin{array}{c}\boldsymbol{H} \\
(\mathbf{m m})\end{array}$ & $\begin{array}{c}\boldsymbol{f}_{\mathbf{c}} \\
(\mathbf{G H z})\end{array}$ \\
\hline Case-1* & 140 & 18 & 35 & 150 & 155 & 2.24 \\
\hline Case-2 & 56 & 6 & 14 & 58 & 60 & 5.62 \\
\hline Case-3 & 37 & 3.5 & 9.5 & 40 & 40 & 8.46 \\
\hline
\end{tabular}

Tab. 1. Physical dimensions and center frequency for Case-1, Case- 2 and Case- 3 .

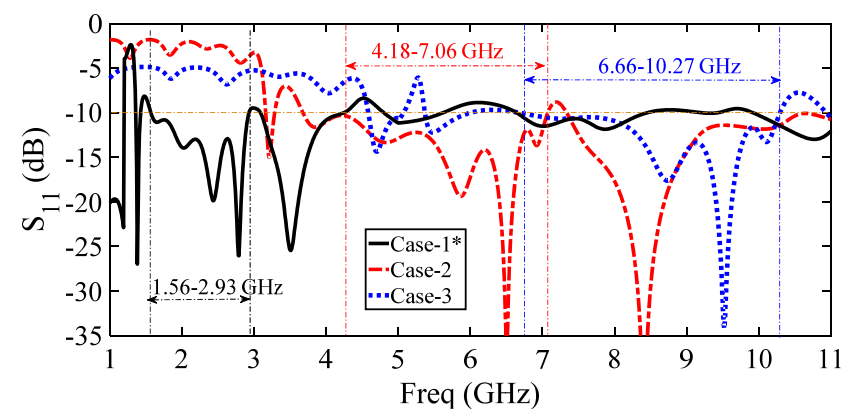

Fig. 2. S-parameters for Case-1, Case-2 and Case-3.

exterior conductor of SMA is soldered to the ground plane. The properties of the helix antenna, such as IBW, ARBW, radiation pattern and gain can be controlled by changing the geometrical parameters and physical dimensions of the helix antenna. These physical parameters are the width of the square ground plane $(G)$, length of the helix arms $(W)$, pitch angle $(\alpha)$, the number of helix turns $(N)$, antenna height $(H)$, and distance between two arms of the helix $(S)$. Likewise, the circumference $(C=4 \times L)$ in one turn of helix is chosen nearly equal to one wavelength $(\lambda)$, while $\lambda$ is the free-space wavelength at the center frequency of bandwidth. The helix antenna has a CP operation in the direction of the helix axis as the circumference of one turn is about $0.75 \lambda<C<1.33 \lambda$ [21]. In this study, three cases of helix antennas with different physical dimensions to achieve several operating frequency bands are investigated. The results of this investigation and the three cases of helix dimensions are tabulated in Tab. 1. It is necessary to explain that parameter $\alpha$ is the same in all cases and equals $14^{\circ}$. As indicated in this table, by decreasing the antenna dimensions, the higher frequencies can be reached. Case-1 refers to the represented helix antenna. Besides, the S-parameter is plotted for Case-1, -2 and -3 in Fig. 2.

\section{Results and Discussion for Helix Antenna}

To explain the effects of the key parameters on the antenna performance, a parametric study is carried out. The important parameters are the circumference of one turn of helix named as $C$ and the number of helix turns named as $N$. The major effect of $C$ is on the antenna operating frequency; this term is investigated in the previous section. Also, the effect of $N$ is studied in this section. Fundamentally, the helix antennas with more turns have a better 


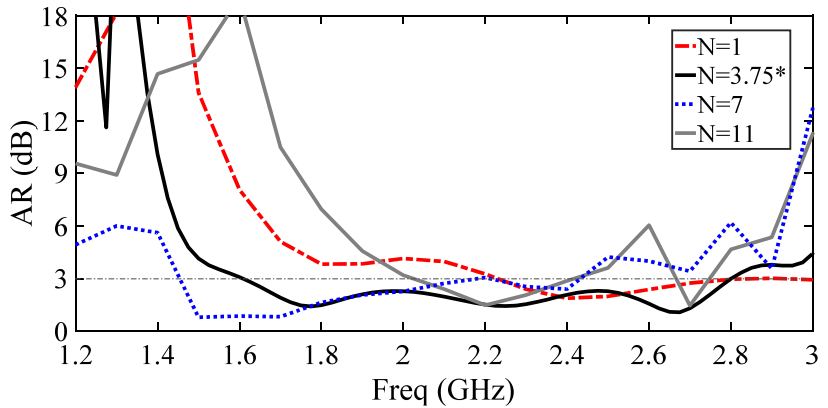

(a)

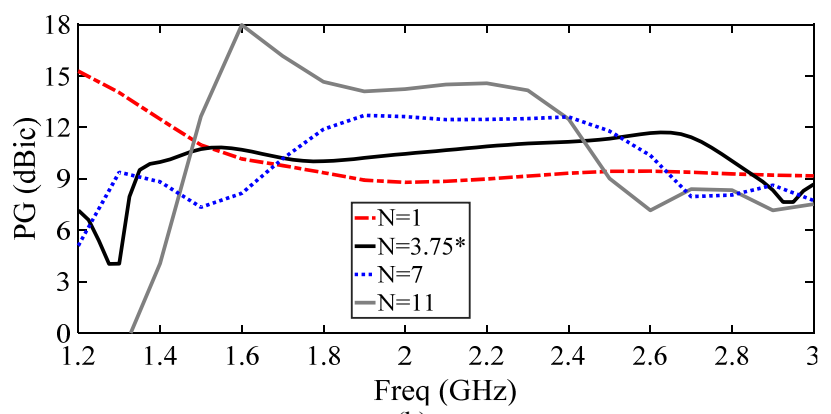

(b)

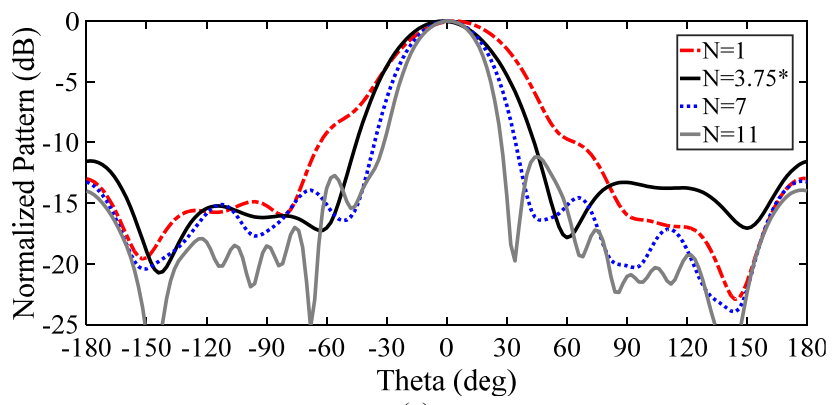

(c)

Fig. 3. Effects of the number of helix turn $N$ on the (a) axial ratio, (b) peak gain, and (c) radiation pattern.

ARBW, radiation pattern, and high gain. Figure 3 illustrates the effects of $N$ on the antenna ARBW, realized peak gain (PG), and radiation pattern. According to Fig. 3(a), the fractional ARBW's are $24 \%, 54 \%, 50 \%$ and $18 \%$ for $N=1,3.75,7$, and 11 , respectively. Additionally, on the basis of the experimental results, the AR features of an axial mode helix antenna are possible to be recuperated by employing incorrect turn at the end of it [9].

Moreover, the averages of the realized peak gains are 9, 11, 12.5, and $14.5 \mathrm{dBiC}$ for $N=1,3.75,7$ and 11, respectively. Figure 3(b) indicates while the value of peak gains for $N=7$ and 11 are more than the others, the stability of the gain at the frequency bandwidth for $N=3.75$ is the best. Likewise, Figure 3(c) depicts a narrower main lobe for a higher number of turns. Correspondingly, the improvement is small when $N$ exceeds 7. This is because the current decays as it travels along the helix [22]. When $N$ is large, the current along the final few turns of the helix is small, slightly play a part in the antenna performance. With respect to these results, we choose $N=3.75$ in our proposed design. Furthermore, so as to show the impact of the incorrect turn at the end of the helix on the antenna
ARBW, Figure 4 is plotted. It is recognizable that the CP operation is better in an incorrect turn.

To attain optimal values for other parameters of the antenna, some parametric studies are carried out. It is observed that the value of $\alpha$ has no significant influence on the IBW and PG, but choosing an accurate value for it leads to a wider AR bandwidth. Figure 5 shows the effect of $\alpha$ on the ARBW.

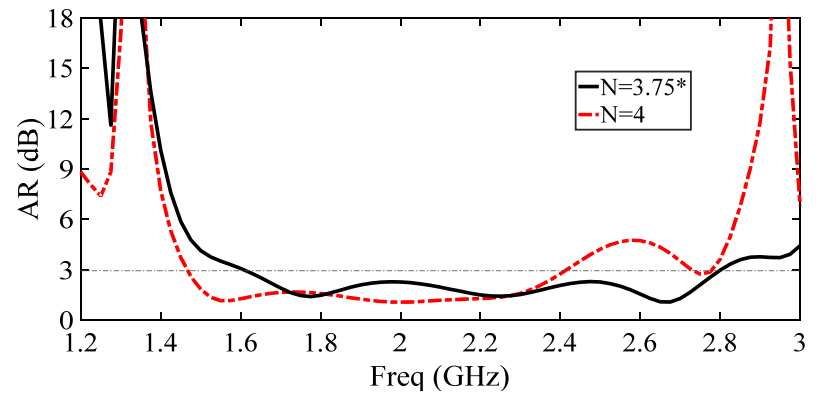

Fig. 4. Axial ratio bandwidths for $N=3.75$ and 4 .

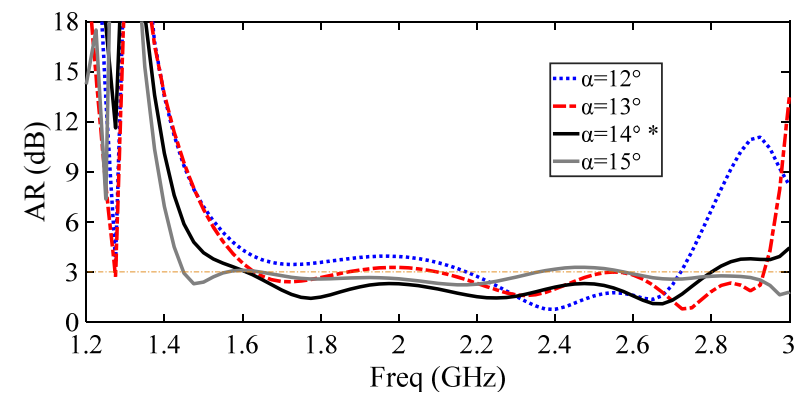

Fig. 5. Effect of the parameter $\alpha$ on the axial ratio.

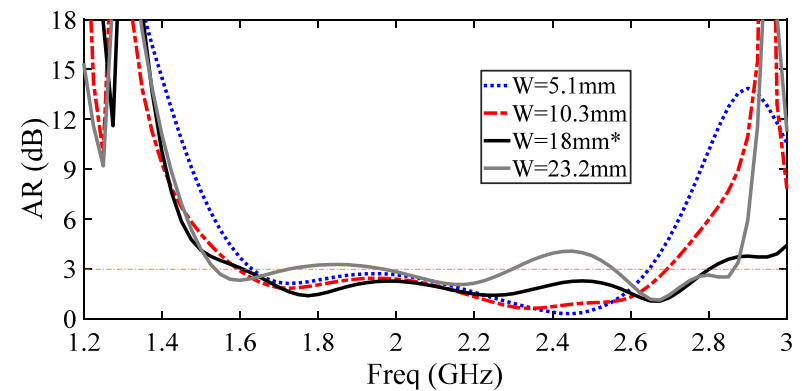

(a)

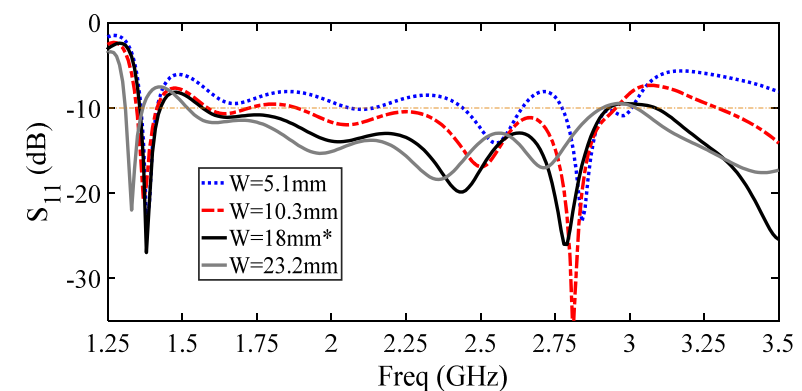

(b)

Fig. 6. Effect of the parameter $W$ on the (a) axial ratio, and (b) $S_{11}$. 


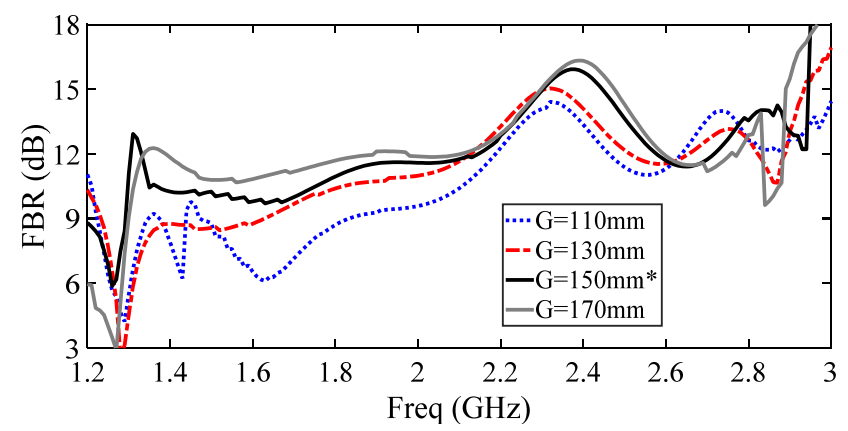

Fig. 7. Effects of the ground dimension on the FBR.

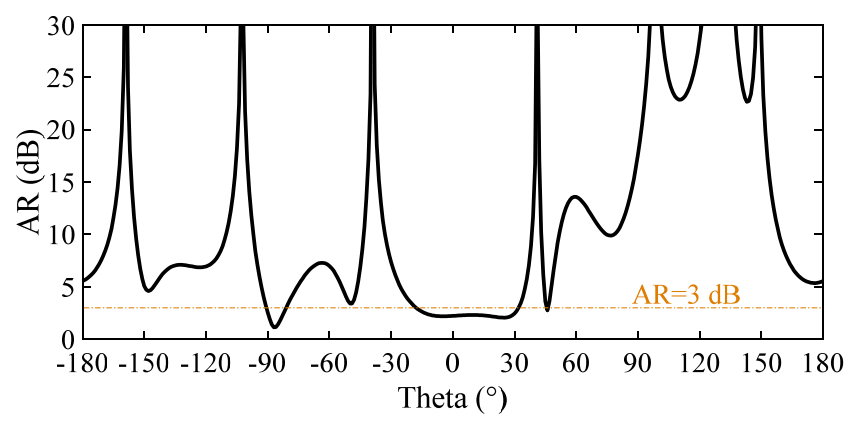

Fig. 8. Simulated AR versus theta angle of the proposed antenna in XZ-plane.

Similarly, it's investigated that the parameter of $W$ does not affect on the PG, and also its effect is remarkable on IBW and AR bandwidth. Regarding Fig. 6, the best value for parameter $W$ is $18 \mathrm{~mm}$ to achieve wide IBW and ARBW simultaneously.

Furthermore, the main mission of the ground plane is producing a directional pattern in the $+Z$ axis. So, the dimension of the ground plane affects the radiation pattern. Consequently, the FBR (Front-to-Back Ratio) response of the antenna with different values for $G$ is plotted. Figure 7 shows that higher FBR attains by a larger ground plane. However, it causes the size and cost of the antenna to increase. So, with a trade-off between the high values for FBR and larger size and higher cost of the system, the parameter of $G$ is set at $150 \mathrm{~mm}$.

Also, the simulated AR versus theta angle of the proposed antenna in XZ-plane is demonstrated in Fig. 8 which shows the beamwidth of $\mathrm{AR}<3 \mathrm{~dB}$ is $49.81^{\circ}$ at $2.4 \mathrm{GHz}$ for proposed helix antenna.

\section{Antenna Fabrication and Measurement}

A prototype of the introduced helix antenna is fabricated and tested to verify the antenna performance. The Sparameter of the offered helix antenna is measured utilizing an Agilent network analyzer E8363C. Figure 9 illustrates the simulated and measured $S_{11}$ responses of the antenna. Referring to the figure, the range of the measured IBW is from $1.72 \mathrm{GHz}$ to $2.84 \mathrm{GHz}$ for $S_{11} \leq-10 \mathrm{~dB}$, whereas the measured result agrees well with the simulated one.

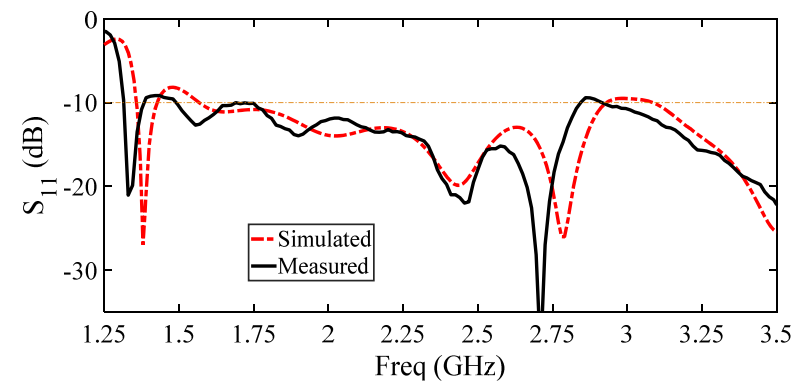

Fig. 9. Simulated and measured S-parameter for the proposed helix antenna.

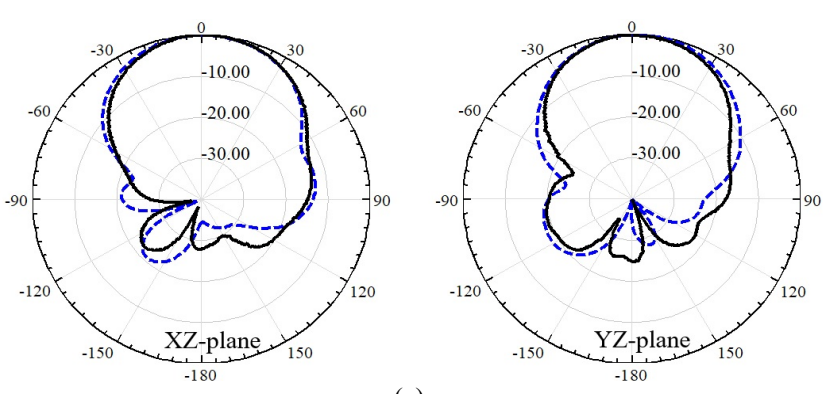

(a)
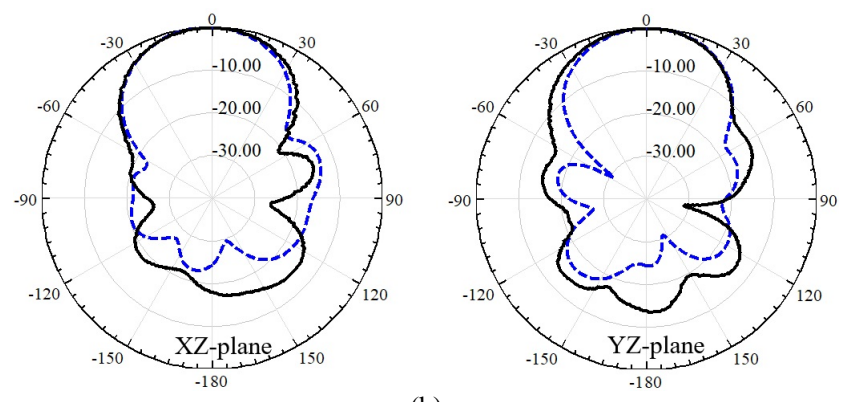

(b)
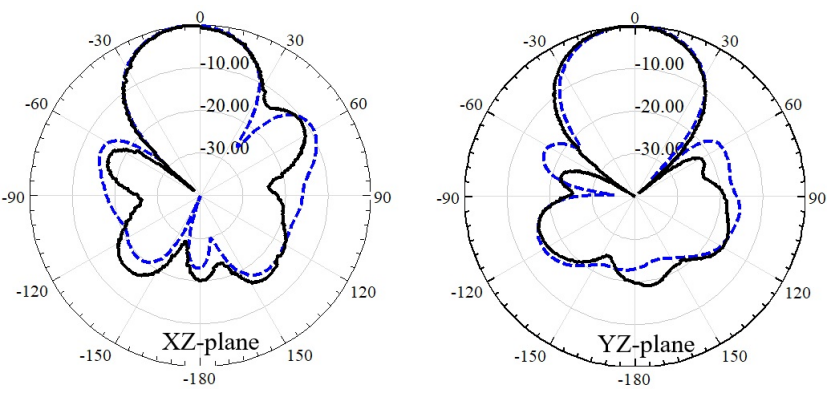

(c)
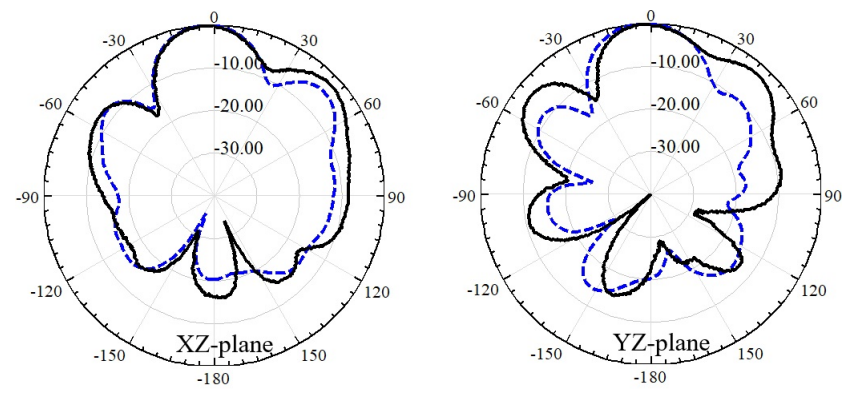

(d)

Fig. 10. Simulated and measured normalized LHCP radiation patterns of the proposed helix antenna in the XZ- and YZ-planes at frequencies of (a) $1.63 \mathrm{GHz}$, (b) $2.05 \mathrm{GHz}$, (c) $2.42 \mathrm{GHz}$, and (d) $2.72 \mathrm{GHz}$. Solid lines are measured results and dash lines are simulated ones, and all the polar axis units are expressed in degree $\left(^{\circ}\right)$. 
Additionally, radiation pattern, axial ratio, and realized peak gain of the introduced helix antenna are tested in an anechoic chamber room in the end-fire direction (Zaxis). The simulated and measured normalized LHCP radiation patterns in the XZ- and YZ-planes at different frequencies are shown in Fig. 10. As seen, end-fire radiations are attained over the frequency bandwidth, simulated and measured results are in a good agreement as well.

Also, the simulated and measured axial ratio and peak gain of the proposed antenna are demonstrated in Fig. 11. According to the simulated result, the ARBW is $54 \%$ which covers from $1.58 \mathrm{GHz}$ to $2.76 \mathrm{GHz}$, while the measured result complies completely with the simulated one.

Also, $10.5 \mathrm{dBiC}$ average measured peak gain is seen in this figure. The measured and simulated gain values have a few differences. This discrepancy can be owing to

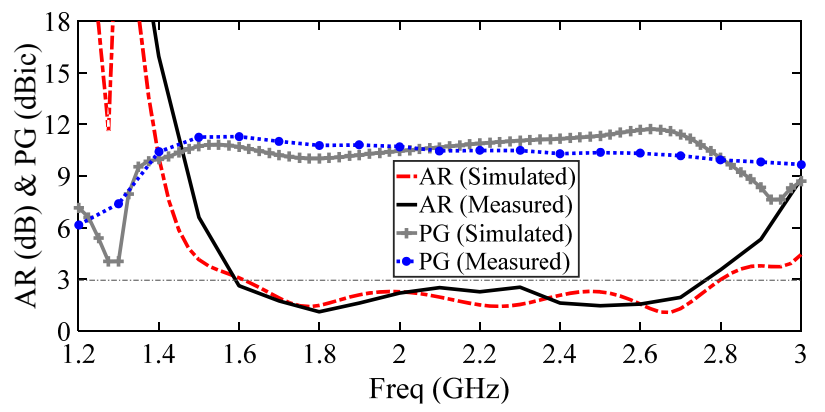

Fig. 11. Simulated and measured axial ratio bandwidth and peak gain of the proposed helix antenna.

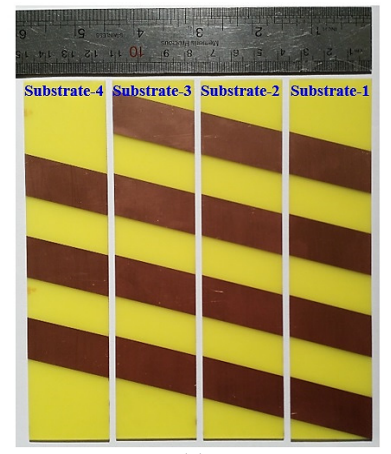

(a)

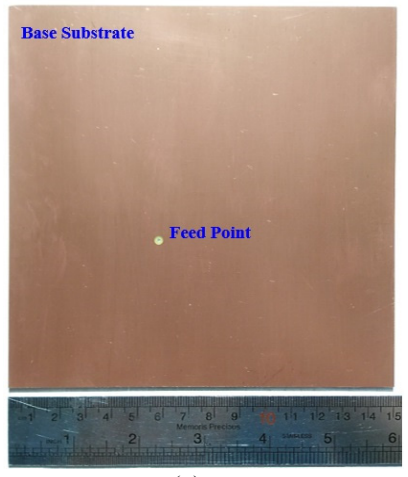

(c)

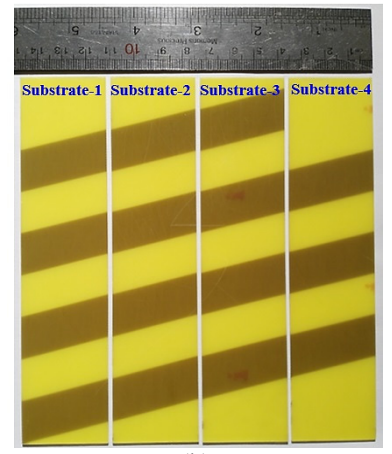

(b)

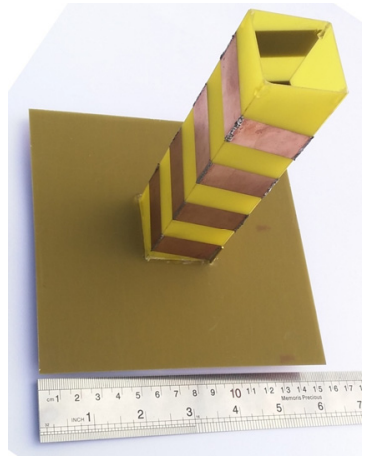

(d)
Fig. 12. Photograph of the printed helix arms on the substrates: (a) front view, (b) back view, (c) photograph of the base substrate and (d) fabricated helix antenna.

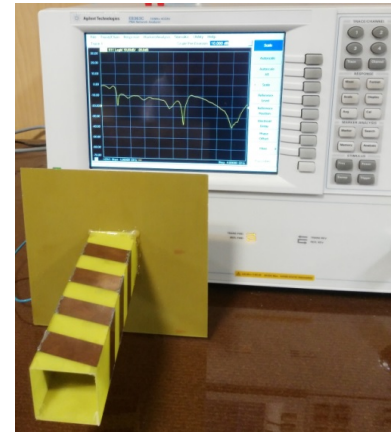

(a)

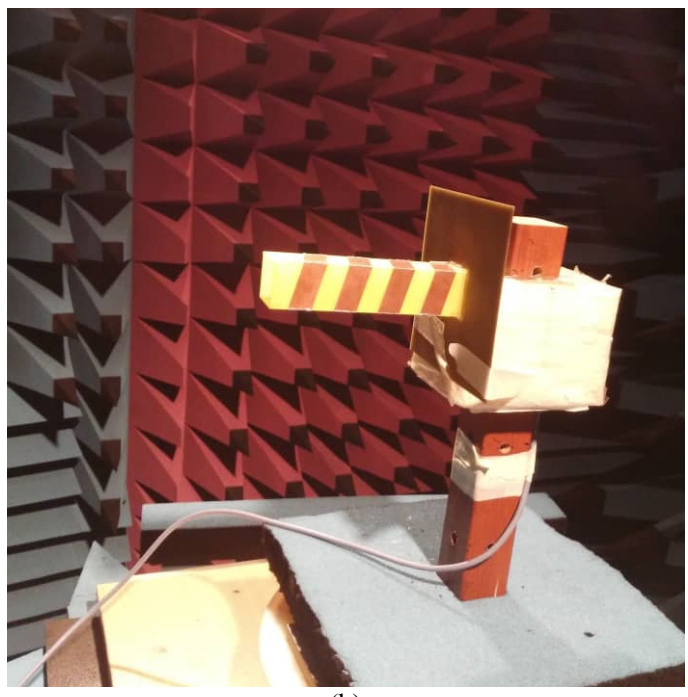

(b)

Fig. 13. (a) The proposed antenna connected to the Network Analyzer, and (b) the anechoic chamber room.

the extra loss inducted by the SMA connector and the alignment inaccuracy of the measurement setup. Figure 12 displays four photographs of the printed arms of the helix on the four substrates named as substrate- 1 to -4 , base substrate and fabricated helix antenna. To assemble the helix antenna, the four substrates, placed vertically next to each other and with soldering the edges of helix arms, are electrically connected to each other. Eventually, the helix main body is mounted perpendicularly on the base substrate and connected to the feed.

Furthermore, two photographs of the fabricated antenna connecting to the Network Analyzer and antenna in the anechoic chamber room are depicted in Fig. 13.

\section{Conclusion}

A new design of printed helix antennas is presented in this paper. The proposed end-fire helix antenna comprises four rectangular substrates placed vertically next to each other and by soldering the edges of helix arms, they are electrically connected to one another. The advantages of this new design are: having a simple structure, ease of fabrication, and solved the impedance matching problem in the feed point. Besides, it is easy to control the antenna operating frequency band by providing a change in helix 
physical parameters. Additionally, the proposed structure has a wide impedance bandwidth of $1.37 \mathrm{GHz}$ (more than $61 \%$ ), the $3 \mathrm{~dB}$ axial ratio bandwidth of $1.18 \mathrm{GHz}$ (more than $54 \%$ ) and a maximum gain of $11.3 \mathrm{dBiC}$ at $1.6 \mathrm{GHz}$. The represented antenna is appropriate for satellite applications at L- and S-bands frequencies.

\section{Acknowledgment}

The authors would like to thank the Northwest Antenna and Microwave Research Laboratory (NAMRL) at Urmia University for technical supports.

\section{References}

[1] MOHAMMADI, S., NOURINIA, J., GHOBADI, C., et al. Compact broadband circularly polarized slot antenna using two linked elliptical slots for C-band applications. IEEE Antennas and Wireless Propagation Letters, 2013, vol. 12, p. 1094-1097. DOI: 10.1109/lawp.2013.2280457

[2] SIAHCHESHM, A., NOURINIA, J., GHOBADI, C., et al. A broadband circularly polarized cavity-backed Archimedean spiral array antenna for C-band applications. AEU - International Journal of Electronics and Communications, 2017, vol. 81, p. 218-226. DOI: 10.1016/j.aeue.2017.08.052

[3] SHOKRI, M., VIRDEE, B., RAFII, V., et al. Miniaturised ultrawideband circularly polarised antenna with modified ground plane. Electronics Letters, 2014, vol. 50, no. 24, p. 1786-1788. DOI: $10.1049 / \mathrm{el} .2014 .3278$

[4] SHOKRI, M., SHIRZAD, H., MOVAGHARNIA, S., et al. Planar monopole antenna with dual interference suppression functionality. IEEE Antennas and Wireless Propagation Letters, 2013, vol. 12, p. 1554-1557. DOI: 10.1109/lawp.2013.2292921

[5] KRAUS, J. D., MARHEFKA, R. J. Antennas for All Applications. Boston (MA, USA): McGraw-Hill, 2008.

[6] CHEN, Z., SHEN, Z. Planar helical antenna of circular polarization. IEEE Transactions on Antennas and Propagation, 2015, vol. 63, no. 10, p. 4315-4323. DOI: 10.1109/tap.2015.2463746

[7] LIU, X., YAO, S., COOK, B. S., et al. An origami reconfigurable axial-mode bifilar helical antenna. IEEE Transactions on Antennas and Propagation, 2015, vol. 63, no. 12, p. 5897-5903. DOI: $10.1109 /$ tap.2015.2481922

[8] TANG, X., HE, Y., FENG, B. Design of a wideband circularly polarized strip-helical antenna with a parasitic patch. IEEE Access, 2016, vol. 4, p. 7728-7735. DOI: 10.1109/access.2016.2628044

[9] FARTOOKZADEH, M., MOHSENI ARMAKI, S. H. Multi-band conical and inverted conical printed quadrifilar helical antennas with compact feed networks. AEU - International Journal of Electronics and Communications, 2016, vol. 70, no. 1, p. 33-39. DOI: $10.1016 /$ j.aeue.2015.09.018

[10] JIMISHA, K., KUMAR, S. Optimum design of exponentially varying helical antenna with non uniform pitch profile. Procedia Technology, 2012, vol. $6, \quad$ p. 792-798. DOI: 10.1016/j.protcy.2012.10.096

[11] ABDERRAHMANE, L. H., SWEETING, M., COOKSLEY, J., et al. Design of a quadrafilar helix antenna used on Alsat-1 S band transmitter. AEU - International Journal of Electronics and
Communications, 2006, vol. 60, no. 8, p. 606-612. DOI: 10.1016/j.aeue.2005.11.011

[12] WONGPAIBOOL, V. Improved axial-mode-helical-antenna impedance matching utilizing triangular copper strip for $2.4-\mathrm{GHz}$ WLAN. In 2008 International Wireless Communications and Mobile Computing Conference. Crete Island (Greece), 2008, p. 869-873. DOI: $10.1109 /$ iwcmc. 2008.150

[13] WONG, J., KING, H. Broadband quasi-taper helical antennas. IEEE Transactions on Antennas and Propagation, 1979, vol. 27, no. 1, p. 72-78. DOI: 10.1109/tap.1979.1142033

[14] ANGELAKOS, D., KAJFEZ, D. Modifications on the axial-mode helical antenna. Proceedings of the IEEE, 1967, vol. 55, no. 4, p. 558-559. DOI: 10.1109 /proc. 1967.5583

[15] KRAUS, J. D. The Helical Antenna: Axial and Other Modes. Part II. In Antenna for All Applications. 3rd ed. McGraw-Hill (New York), 2003. Ch. 8, p. 250-303.

[16] BALANIS, C. A. Traveling Wave and Broadband Antennas. In Antenna Theory, Analysis and Design. 3rd ed. New York: John Wiley \& Sons, 1997. Ch. 10, p. 549-610.

[17] KRAUS, J. A 50-ohm input impedance for helical beam antennas. IEEE Transactions on Antennas and Propagation, 1977, vol. 25, no. 6, p. 913-913. DOI: 10.1109/tap.1977.1141687

[18] BARTS, R. M. The Stub Loaded Helix: A Reduced Size Helical Antenna. Ph.D. dissertation. Virginia Polytechnic Institute and State University, Blacksburg, VA, 2003.

[19] MATHUR, S. P., SINHA, A. K., SINHA, A. K. Technical memorandum: Design of microstrip exponentially tapered lines to match helical antennas to standard coaxial transmission lines. IEE Proceedings H Microwaves, Antennas and Propagation, 1988, vol. 135, no. 4, p. 272-274. DOI: 10.1049/ip-h-2.1988.0055

[20] TSANDOULAS, G. N. The linearly tapered transmission line as a matching section-High- and low-frequency behavior. Proceedings of the IEEE, 1967, vol. 55, no. 9, p. 1658-1659. DOI: 10.1109/proc.1967.5950

[21] MANOOCHEHRI, O., ABBASINIAZARE, S., FOROORAGHI, K. Design of a $2 \times 2$ tapered dielectric-loaded helical antenna array for INMARSAT-M satellite system. Microwave and Optical Technology Letters, 2013, vol. 55, no. 11, p. 2600-2604. DOI: 10.1002/mop.27904

[22] NAKANO, H., TAKEDA, H., HONMA, T., et al. Extremely lowprofile helix radiating a circularly polarized wave. IEEE Transactions on Antennas and Propagation, 1991, vol. 39, no. 6, p. $754-757$. DOI: $10.1109 / 8.86872$

\section{About the Authors ...}

Amir SIAHCHESHM (corresponding author) was born in Urmia, Iran in 1981. He received the B.Sc. degree in Communication Engineering from Islamic Azad University of Urmia, Iran (2003) and M.Sc. degree (with honors) from Urmia University, Iran in Communication Engineering (2007). He received his Ph.D. degree from the Department of Electrical Engineering, Urmia University in 2018. Meanwhile he is a lecturer at Electrical Engineering Department of Islamic Azad University of Salmas, Iran from 2009. And now he is an assistant professor. His research interests include antenna design, wireless systems, array antennas and circular polarization. 
Javad NOURINIA received his B.Sc. in Electrical and Electronic Engineering from Shiraz University and M.Sc. degree in Electrical and Telecommunication Engineering from Iran University of Science and Technology, and $\mathrm{Ph}$.D. degree in Electrical and Telecommunication from University of Science and Technology, Tehran, Iran in 2000. From 2000 he was an assistant professor and now he is a professor in the Department of Electrical Engineering of Urmia University, Urmia, Iran. His primary research interests are in antenna design, numerical methods in electromagnetic, microwave circuits.

Changiz GHOBADI was born in Iran on 1 June, 1960. He received his B.Sc. in Electrical Engineering-Electronics and M.Sc. degrees in Electrical Engineering from Isfahan University of Technology, Isfahan, Iran and Ph.D. degree in Electrical-Telecommunication from University of Bath, Bath, UK in 1998. From 1998 he was an assistant professor and now he is a professor in the Department of Electrical Engineering of Urmia University, Urmia, Iran. His primary research interests are in antenna design, radar and adaptive filters.

Majid SHOKRI was born in Urmia, Iran in 1979. He received the B.Sc. and M.Sc. degrees from the Urmia Branch, IAU and Urmia University in 2001 and 2012, respectively, both in Electrical and Communication Engineering. Since 2018 he is pursuing the Ph.D. degree in Communication Engineering with the Department of Electrical Engineering, Urmia University. His areas of interests are microstrip antennas, circularly polarized antennas and microwave circuits. 